Research Article

\title{
Physicochemical Characterization of Regional Clay: Application to Phenol Adsorption
}

\author{
Abdelouahed Amar $\left(\mathbb{D},{ }^{1}\right.$ Ilyasse Loulidi, ${ }^{1}$ Abderrahim Kali, ${ }^{1}$ Fatima Boukhlifi, ${ }^{1}$ \\ Chaimaa Hadey, ${ }^{2}$ and Maria Jabri ${ }^{1}$ \\ ${ }^{1}$ Laboratory of Chemistry and Biology Applied to the Environment, Faculty of Sciences, Moulay Ismail University, \\ BP 11201-Zitoune, Meknes, Morocco \\ ${ }^{2}$ Engineering Sciences and Trades Laboratory, ENSAM, University Moulay Ismail, Meknes, Morocco
}

Correspondence should be addressed to Abdelouahed Amar; a.amar@edu.umi.ac.ma

Received 19 April 2020; Revised 23 March 2021; Accepted 12 April 2021; Published 4 May 2021

Academic Editor: Amaresh K. Nayak

Copyright (c) 2021 Abdelouahed Amar et al. This is an open access article distributed under the Creative Commons Attribution License, which permits unrestricted use, distribution, and reproduction in any medium, provided the original work is properly cited.

\begin{abstract}
Phenol is one of the most toxic pollutants found in industrial waste. This work focuses on the removal of phenol using clay from the Sale region. Adsorbent was characterized by X-ray fluorescence spectroscopy, X-ray diffraction, infrared spectroscopy, and scanning electron microscopy. The chemical analysis of this clay shows that the percentage of silicon and aluminium is quite high, and the percentage of calcium and iron is relatively high, so this material is rich in muscovite, quartz, and calcite. In addition to the presence of titanium dioxide $\left(\mathrm{TiO}_{2}\right)$, which can give it a property of degradation of organic compounds under ultraviolet light, the $\mathrm{pH}_{\mathrm{PZC}}$ zero point of our material is 7.4. The results showed that the adsorption of phenol was well fitted by the pseudo-secondorder kinetic model and the Langmuir and Freundlich isotherms and that the best retention is obtained at a pH between 3 and 8 .
\end{abstract}

\section{Introduction}

The pollution of water by certain organic and inorganic chemicals is a serious source of degradation of our environment. Among these products is phenol, which is the product used in some industrial sectors in the region, such as the industry of plastics, synthetic petroleum fibres, detergents, and the industry of dyes and oil additives [1]. The effluents of the above sectors are loaded by phenolic compounds, which are spilled into wastewater networks and are in turn spilled into marine areas or rivers, producing adverse effects for human health as well as disruption of ecosystem life cycles. Concentration of $1 \mu \mathrm{g} \cdot \mathrm{L}^{-1}$ is the maximum permissible amount of phenol in drinking water according to the World Health Organization [2]; also phenols are classified among the priority pollutants by the U.S. Environmental Protection Agency [3]. Faced with this problem, two techniques are applied: destructive techniques [4], such as thermal oxidation and catalytic oxidation [5], and recovery techniques, such as adsorption [6], precipitation [7], separation by membrane, and ion exchange [8]. Adsorption is among the most used techniques for the recovery of some organic and inorganic chemicals, thanks to its ease and simplicity unit operation $[9,10]$. Nowadays activated carbon is the strongest adsorbent used for water purification and the removal of organic matter [11]. But the high price of activated carbon has prompted many researchers to look for other alternatives. The abundance of many cheaper materials in nature attracted the attention of many researchers including Chaari et al. [12, 13], Bentahar et al. [14], Sakin Omer et al. [15], Khosla [16], and Kyzioł-Komosinska et al. [17]. Clay materials have a good adsorption capacity of organic pollutants, heavy metals, and dyes to aqueous media [18]. Several studies have been targeted by the use of Moroccan clay adsorbent for the recovery of methylene blue [19], basic yellow cationic dye [20], methyl violet [19], adsorption of amino acids [21], adsorption of gallic acid on montmorillonite [22], adsorption of acid dyes red 1 and acid 
green 25 [23], removal of phenol and its derivatives by adsorption on petroleum asphalts [3], and adsorption of phenol by modified bentonite [24].

The surface charge of a clay material and its structure and chemical composition are parameters sufficiently capable of determining their adsorption capacity [25]. Note that $2: 1$ clay materials have higher adsorption capacities than $1: 1$ materials that adsorb species on the external surface [26].

In the present work, we aimed at the physicochemical characterization of a regional raw clay and its application to the adsorption of phenol in a liquid medium.

\section{Materials and Methods}

2.1. Material. In this study, we used a clay from the city of Sale located in the region of Rabat-Sale-Kenitra. It is located on the Atlantic Ocean, on the right bank (north) of the mouth of the Bouregreg River, opposite Rabat, the national capital of Morocco (Figure 1).

2.2. Characterization of the Adsorbent. The adsorbent used in this study was characterized, before and after its contact with phenol, by X-ray Diffraction (XRD), Fourier Transform Infrared Spectroscopy (FTIR), and scanning electron microscopy (SEM). The FTIR spectrum of the studied sample was performed using Fourier Transform Infrared Spectrometer (Shimadzu FTIR, JASCO 4100) in the range from 400 to $4000 \mathrm{~cm}^{-1}$.

2.3. Adsorption Tests. A mass $m=0.05 \mathrm{~g}$ of the adsorbent was mixed with $V=20 \mathrm{~mL}$ of a synthetic phenol solution with an initial concentration of $10-3(\mathrm{~mol} / \mathrm{L})$. The mixture was then stirred for a well-determined contact time and after separation of the solid by centrifugation. The phenol remaining in the solution was analyzed with the UV/Visible Spectrophotometer (Shimadzu UV-1240) at a wavelength equal to $270 \mathrm{~nm}$, and the amount of adsorbed phenol was calculated by the following equation [27]:

$$
Q_{e}=\frac{C_{0}-C_{e}}{m} \times V,
$$

where $Q_{e}$ denotes amount of pollutant adsorbed at equilibrium $\left(\mathrm{mg} \mathrm{g}^{-1}\right) ; C_{0}$ denotes initial concentration $\left(\mathrm{mg} \mathrm{L}^{-1}\right)$; $C_{e}$ denotes concentration of the solute in the solution at equilibrium ( $\left.\mathrm{mg} \mathrm{L}^{-1}\right) ; V$ denotes volume of the solution $(\mathrm{L})$; and $m$ denotes mass of the adsorbent (g).

Kinetic adsorption experiments were performed to establish the effect of time on adsorption, and equilibrium experiments were performed to establish the adsorption isotherms. The thermodynamic study was done at different temperatures $\left(20^{\circ} \mathrm{C}, 30^{\circ} \mathrm{C}\right.$, and $\left.60^{\circ} \mathrm{C}\right)$. Initially, experiments were performed at $20^{\circ} \mathrm{C}$ to study the effects of contact time and $\mathrm{pH}$. The conditions were $\mathrm{pH} 6.0$ and contact time of $90 \mathrm{~min}$.

The removal efficiency of phenol on the adsorbent, $R \%$, was calculated by the following equation [28]:

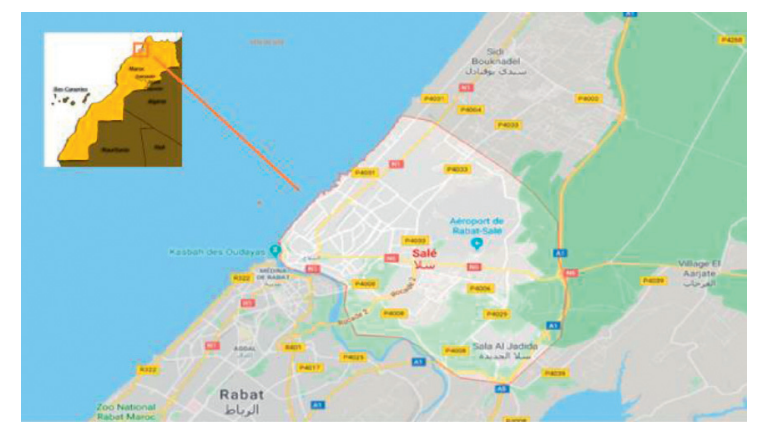

FIgURE 1: Location of the city of Sale on the graphic map of Morocco.

$$
R \%=\frac{C_{0}-C_{e}}{C_{0}} \times 100,
$$

where $C_{0}$ and $C_{e}$ are, respectively, the initial and equilibrium concentrations of the adsorbate $(\mathrm{mg} / \mathrm{L})$, respectively.

Table 1 presents the equations of the models used in this work [29].

$q_{t}\left(\mathrm{mg} \cdot \mathrm{g}^{-1}\right)$ and $q_{e}\left(\mathrm{mg}^{-1} \mathrm{~g}^{-1}\right)$ are the quantities of adsorbed phenol at time $t$ and at equilibrium; $k_{1}\left(\mathrm{~min}^{-1}\right)$ and $k_{2}$ $\left(\mathrm{g} \cdot \mathrm{mg}^{-1} \cdot \mathrm{min}^{-1}\right.$ ) are the constants of pseudo-first-order and pseudo-second-order models, respectively. $C_{e}(\mathrm{mg} / \mathrm{L})$ is the equilibrium concentration; $q_{m}(\mathrm{mg} / \mathrm{g})$ is the maximum adsorption capacity; $K_{L}(\mathrm{~L} / \mathrm{mg})$ is the Langmuir constant; $K_{F}$ $\left(\mathrm{mg}^{-1}\right)\left(\mathrm{L} \cdot \mathrm{mg}^{-1}\right)^{1 / n}$ and $n$ are the Freundlich constants.

\section{Results and Discussions}

3.1. Chemical Composition of the Adsorbent. Our material has undergone analytical techniques that highlight its physical and chemical properties and is studied at the molecular level using X-ray spectroscopy, X-ray diffraction, and infrared spectroscopy (IR). The chemical analysis of the raw clay sample (Table 2) shows that the percentage of silicon and aluminium is quite high, and the percentage of calcium and iron is relatively high, so this material is rich in muscovite, quartz, and calcite. In addition, the presence of titanium dioxide $\left(\mathrm{TiO}_{2}\right)$ can give it a property of degradation of organic compounds under ultraviolet light.

3.2. Analysis by X-Ray Diffraction. The X-ray diffraction spectrum is shown in Figure 2.

The X-ray diffraction spectrum (Figure 2) shows that this clay is a mixture of

(1) Quartz $\left(\mathrm{SiO}_{2}\right)$

(2) Calcite $\left(\mathrm{Ca}\left(\mathrm{CO}_{3}\right)\right)$

(3) Muscovite $\left(\mathrm{H}_{4} \mathrm{~K}_{2}(\mathrm{Al}, \mathrm{Fe})_{6} \mathrm{Si}_{6} \mathrm{O}_{24}\right)$

3.3. Scanning Electron Microscopy. Scanning electron microscopy analysis of materials used in this study was performed to obtain additional information about their morphologies. Figure 3 shows the images obtained by scanning electron microscopy; it is apparent that the shape of the sample is dispersed and characterized by grains whose 
TABLE 1: The equations of the models used in this work.

\begin{tabular}{lr}
\hline Kinetic models & - \\
Pseudo-first-order & $\left(\mathrm{d} Q_{t} / \mathrm{d} t\right)=k_{1}\left(Q_{e}-Q_{t}\right)$ \\
Pseudo-second-order & $\left(\mathrm{d} Q_{t} / \mathrm{d} t\right)=k_{2}\left(Q_{e}-Q_{t}\right)^{2}$ \\
\hline Isotherm models & - \\
Langmuir & $Q_{e}=\left(Q_{m} \cdot K_{L} \cdot C_{e} / 1+K_{L} \cdot C_{e}\right)$ \\
Freundlich & $Q_{e}=K_{F} \cdot C_{e}^{(1 / n)}$ \\
\hline
\end{tabular}

TABLE 2: Chemical composition by carrier X-ray fluorescence spectroscopy.

\begin{tabular}{|c|c|c|c|c|c|c|c|c|c|c|c|c|c|c|}
\hline Compound & $\mathrm{SiO}_{2}$ & $\mathrm{Al}_{2} \mathrm{O}_{3}$ & P.a.F & $\mathrm{CaO}$ & $\mathrm{Fe}_{2} \mathrm{O}_{3}$ & $\mathrm{~K}_{2} \mathrm{O}$ & $\mathrm{MgO}$ & $\mathrm{TiO}_{2}$ & $\mathrm{Na}_{2} \mathrm{O}$ & $\mathrm{P}_{2} \mathrm{O}_{5}$ & $\mathrm{SO}_{3}$ & $\mathrm{SrO}$ & $\mathrm{Rb}_{2} \mathrm{O}$ & $\mathrm{ZrO}_{2}$ \\
\hline Conc. (\%) & 66.23 & 11.99 & 7.97 & 4.54 & 4.29 & 1.67 & 1.56 & 0.74 & 0.60 & 0.17 & 0.13 & 0.09 & 0.01 & 0.004 \\
\hline
\end{tabular}

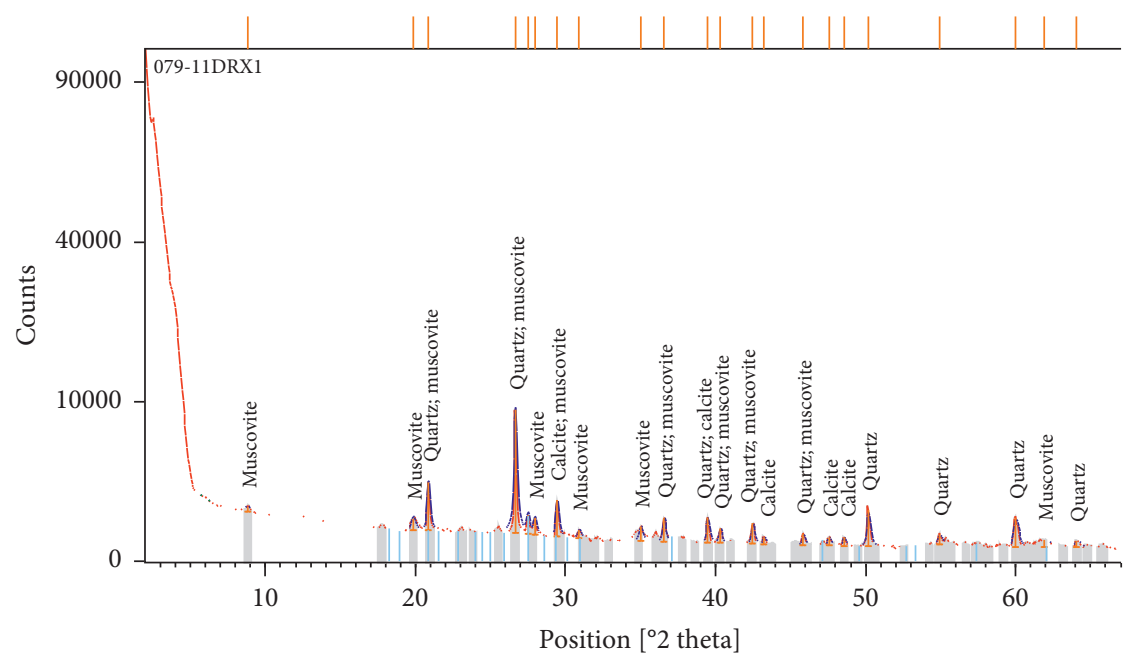

Figure 2: X-ray diffraction spectrum of Sale clay.

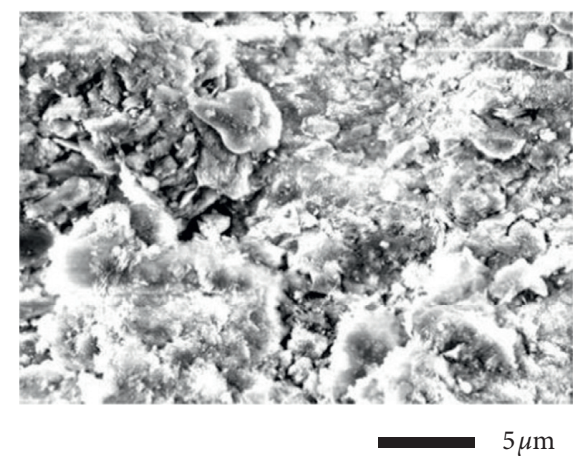

(a)

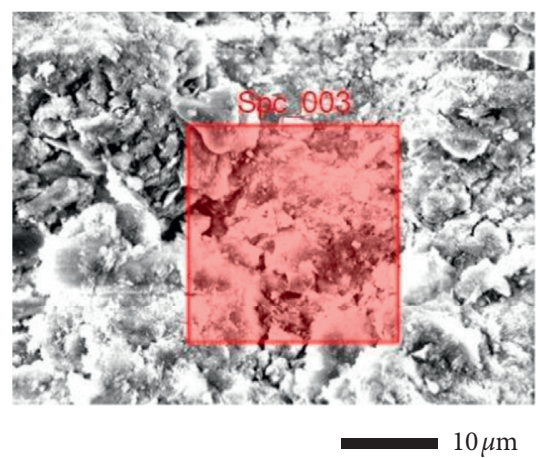

(b)

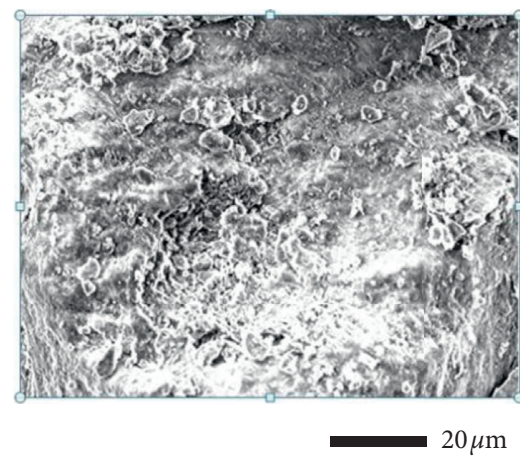

(c)

FIgURE 3: SEM images of the salt clay.

size is between 2 and $4 \mu \mathrm{m}$. These grains are characterized by the presence of various microcavities and large pores that are favorable for the diffusion of phenol molecules [2].

The local analysis performed by EDXS (Figure 4 and Table 3 ) is in fairly good agreement with those of X-ray diffraction (Figure 2) [2]. Salt clay has a porous rock surface form with significant structural shapes that can adsorb phenol.
3.4. Infrared Analysis. The infrared spectrum of our adsorbent is displayed below.

Figure 5 represents the infrared spectra of the Sale clay before and after the adsorption of phenol. According to this analysis, one observes on the two infrared spectra of material two adsorption bands characterizing the $\mathrm{O}-\mathrm{H}$ bonds located, respectively, between 3200 and $3800 \mathrm{~cm}^{-1}$. Another average band between 1600 and $1700 \mathrm{~cm}^{-1}$ is attributed to the 


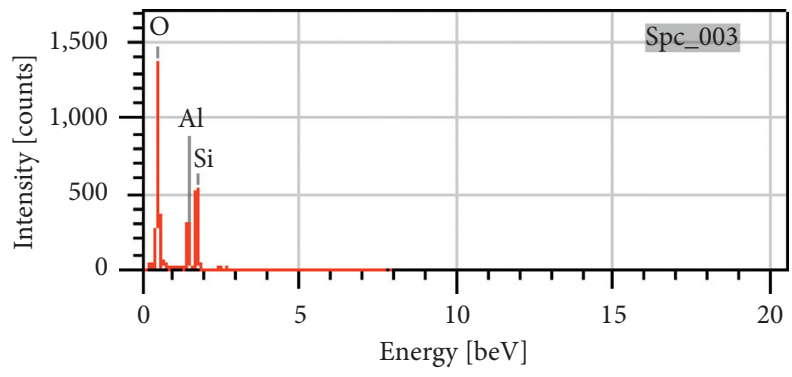

FIgURE 4: EDX diagram of Safi clay.

TABLE 3: Elemental analysis of the clay surface.

\begin{tabular}{lccc}
\hline Element & Line & Mass \% & Atom \% \\
\hline $\mathrm{O}$ & $\mathrm{K}$ & $58.02 \pm 0.51$ & $70.57 \pm 0.62$ \\
$\mathrm{Al}$ & $\mathrm{K}$ & $12.07 \pm 0.31$ & $8.71 \pm 0.22$ \\
$\mathrm{Si}$ & $\mathrm{K}$ & $29.90 \pm 0.53$ & $20.72 \pm 0.37$ \\
\hline
\end{tabular}

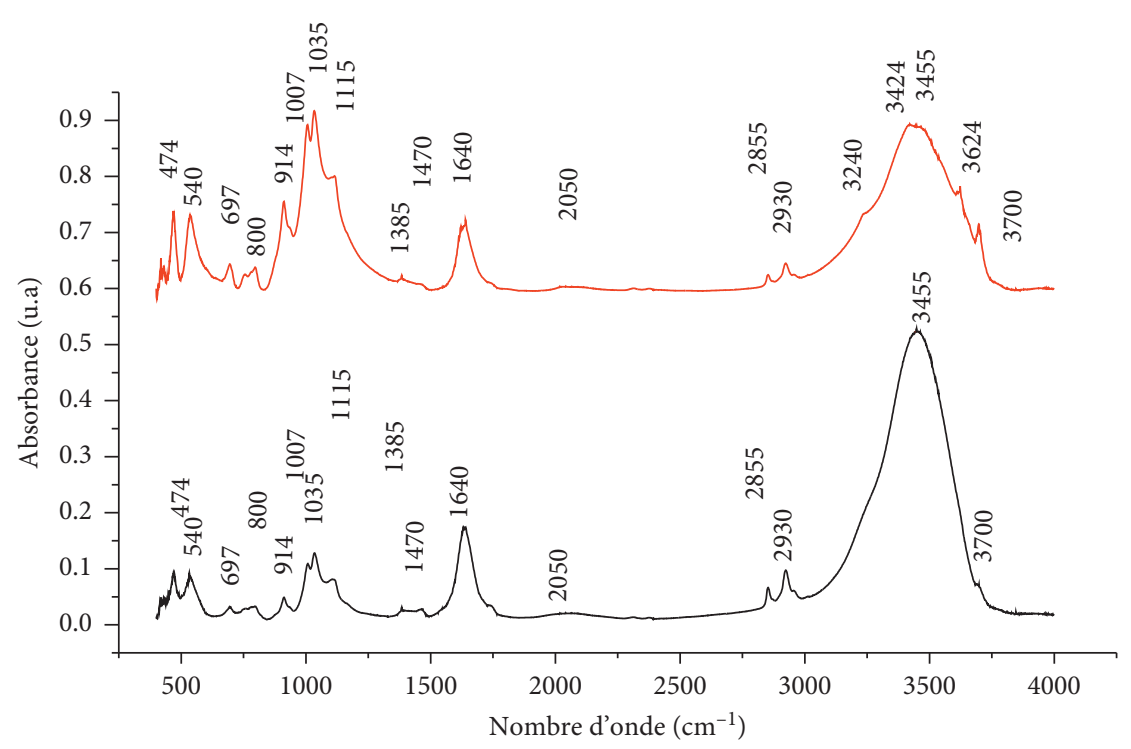

Figure 5: Infrared spectrum of Sale clay before and after phenol adsorption.

deformation vibrations of the $\mathrm{O}-\mathrm{H}$ bond of the water of constitution and to the deformation vibrations of the bonds of the water molecules adsorbed between the sheets. There is also an intense adsorption band between 900 and $1200 \mathrm{~cm}^{-1}$. This band is centered on $1035 \mathrm{~cm}^{-1}$, and it characterizes the valence vibrations of the $\mathrm{Si}-\mathrm{O}$ bond. The bands of vibration of these bonds $\mathrm{Si}-\mathrm{O}-\mathrm{Al}, \mathrm{Si}-\mathrm{O}-\mathrm{Mg}$, and $\mathrm{Si}-\mathrm{O}-\mathrm{Fe}$, appear in the interval of $400-550 \mathrm{~cm}^{-1}$ [2], while for the spectrum of infrared after the adsorption we note the appearance of a band towards $3324 \mathrm{~cm}^{-1}$ which characterizes the valence vibrations of the $\mathrm{O}-\mathrm{H}$ bond.

3.5. Determination of the Zero Charge Point (PZC). The point of zero charge $\mathrm{pH}_{\mathrm{pzc}}$ is the parameter corresponding to the $\mathrm{pH}$ for which the surface of the solid presents a zero charge.
If the hydrogen potential $(\mathrm{pH})$ is lower than $\mathrm{PZC}$, then the net charge is positive, and if the $\mathrm{pH}$ is higher than $\mathrm{PZC}$, then the net charge is negative.

To determine the point of zero charge (PZC) of our material, we use the Drift method [30], which consists of preparing five samples of $50 \mathrm{ml}$ of $0.01 \mathrm{M} \mathrm{NaCl}$ solution; for the stabilization of the $\mathrm{pH}$, the samples must be bubbled with nitrogen, using a few drops of $\mathrm{HCl}$ and/or $\mathrm{NaOH}$ to adjust the $\mathrm{pH}$ of four samples, two of which are in the acidic zone and the other two are basic. The fifth sample, which has an intermediate $\mathrm{pH}$, is left as a reference; then $0.15 \mathrm{~g}$ of the product is added to each sample, and the final $\mathrm{pH}$ is measured after 24 hours of agitation.

To determine the point of zero charge (PZC), we draw the curve $\mathrm{pH}_{f}=f\left(\mathrm{pH}_{i}\right)$, the point $\mathrm{pH}_{\mathrm{pzc}}$ is the intersection of 
this curve with the right $\mathrm{pH}_{i}=\mathrm{pH}_{f}$, and we find that $\mathrm{pH}_{\mathrm{pzc}}$ of the material is 7.4 (Figure 6).

\section{Adsorption Kinetics of the Adsorbate on the Material}

The results of the experiments related to the effect of time on the adsorption of phenol on clay are shown in Figure 7 . According to Figure 7, the adsorption capacity increases very rapidly with time until equilibrium is reached after 20 minutes. Indeed, from this moment on, almost all the available sites on the surface of the adsorbent are occupied by phenol.

\subsection{Adsorption Kinetics of the Different Granulometries of} Material. Figure 8 shows that the adsorbed amount of phenol on different particle sizes of this clay is almost the same. This explains that the particle size for this adsorbent has no effect.

4.2. Determination of the Order of the Adsorption Reaction. Modeling of the phenol adsorption kinetics was done using the first-order (Lagergren model) and second-order (Ho et al.'s model) kinetic equations.

4.2.1. Pseudo-First-Order Model. The graphical representation of the pseudo-first-order equation (Lagergren) is given in Figure 9.

The plot of $\ln \left(Q_{\mathrm{abs}}-Q_{t}\right)$ versus time $(t)$ (Figure 9) shows a straight line with a regression coefficient equal to 0.99 ; Table 4 groups the parameters of the graphical representation of the pseudo-first-order equation (Lagergren).

The correlation coefficient is $R^{2}=0.99$, which confirms the straight line pattern obtained; however, the calculation of the adsorbed quantity $\left(Q_{e}\right)$ shows that the theoretical adsorbed quantity is rather low compared to the experimental quantity. The relative differences between the values of the quantity of adsorption $\left(Q_{e}\right)$ were determined experimentally and were theoretically strong $(>97 \%)$; these observations lead us to say that the adsorption of phenol on this clay does not express a process of controlled diffusion since it does not follow the equation of the pseudo-first-order, given by Lagergren.

4.2.2. Pseudo-Second-Order Model. The graphical representation of the pseudo-second-order equation (Ho et al.) is given in Figure 10.

Figure 10 shows the application of the pseudo-secondorder kinetics model to the result obtained for the adsorption of phenol. The straight line obtained is perfectly linear with a correlation coefficient closer to 1 . The theoretical and experimental adsorbed quantity $\left(Q_{e}\right)$ values, the pseudo-second-order constant $K_{2}$, and the regression coefficient $R^{2}$ for this adsorbent used are displayed in Table 5.

From these results, it appears that the calculated adsorbed quantity $\left(Q_{e}\right)$ of the order of $17.89 \mathrm{mg} / \mathrm{g}$ is closer to that of the experimental adsorbed quantity $\left(Q_{e}\right)$ whose value

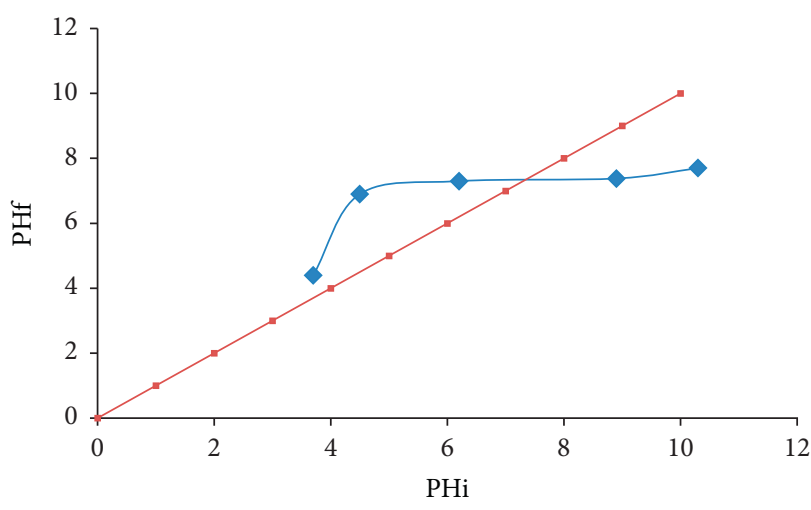

Figure 6: pH zero point determination curve.

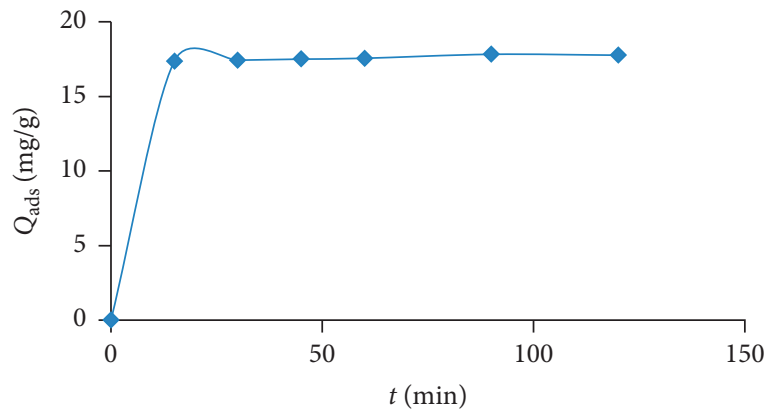

FIGURE 7: Influence of contact time on the adsorption of phenol on Sale clay.

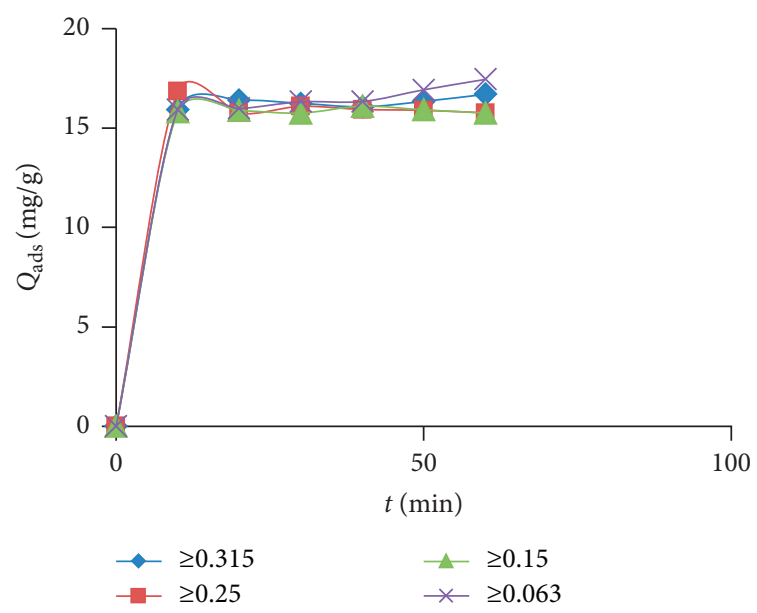

FIGURE 8: Influence of contact time on the adsorption of phenol on different granulometries of the sale clay.

is of the order of $17.55 \mathrm{mg} / \mathrm{g}$, which explains the small relative difference between these two quantities; therefore, the pseudo-second-order model is the most suitable to describe the kinetics of adsorption of phenol on this adsorbent support.

4.2.3. Adsorption Isotherm Study. The study of the phenol adsorption isotherm was carried out under the same experimental conditions as the kinetic study, and the modeling 


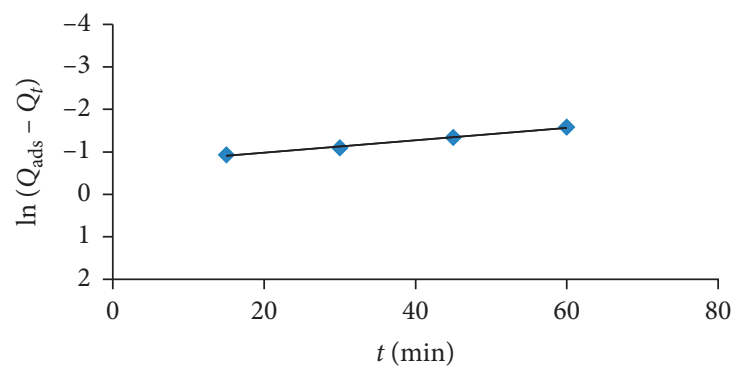

Figure 9: Pseudo-first-order model related to the adsorption kinetics of phenol on the adsorbent support (Lagergren model).

TABLE 4: Parameters of the graphical representation of the Largergren equation for the adsorption kinetics of phenol.

\begin{tabular}{lcccc}
\hline$R^{2}$ & $K_{2}\left(\mathrm{~min}^{-1}\right)$ & Experimental $Q_{e}\left(\mathrm{mg} \cdot \mathrm{g}^{-1}\right)$ & Calculated $Q_{e}\left(\mathrm{mg}^{-1} \mathrm{~g}^{-1}\right)$ & Relative deviation $(\%)$ \\
\hline 0.99 & 0.015 & 17.55 & 0.50 & 97.15 \\
\hline
\end{tabular}

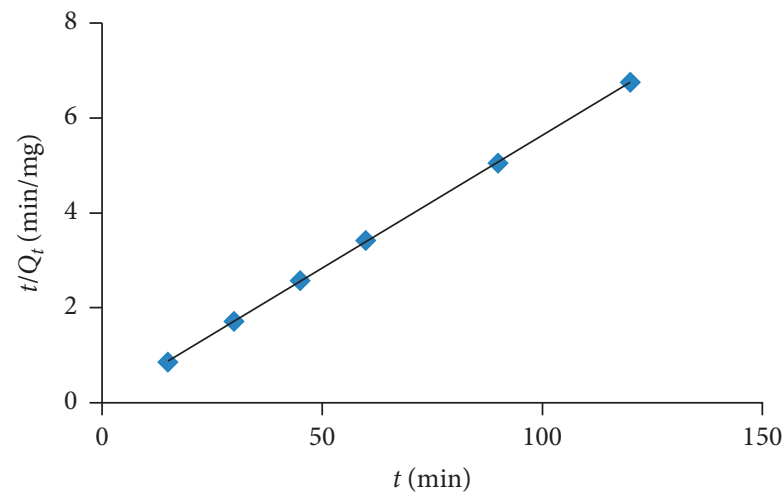

FIgURE 10: Pseudo-second-order model for the adsorption kinetics of phenol on the adsorbent support (equation of Ho et al.).

TABle 5: Parameters of the graphical representation of the equation of Ho et al. for the adsorption kinetics of phenol.

\begin{tabular}{ccccc}
\hline$R^{2}$ & $K_{2}\left(\mathrm{~min}^{-1}\right)$ & Experimental $Q_{e}\left(\mathrm{mg}^{-1}\right)$ & Calculated $\mathrm{Q}_{e}\left(\mathrm{mg} \cdot \mathrm{g}^{-1}\right)$ & Relative deviation $(\%)$ \\
\hline 0.99 & 0.075 & 17.55 & 17.89 & 1.94 \\
\hline
\end{tabular}

of the phenol adsorption isotherm was done using the Langmuir and Freundlich models.

Graphical representations of the Langmuir and Freundlich models adsorption isotherm are shown in Figures 11 and 12:

From the results obtained for the two models studied, we can say that the adsorption of phenol on our clay support in the range of initial concentrations studied can be described by the Langmuir and Freundlich models, indicating that the phenol molecules are adsorbed on the material surface without interactions on energetically homogeneous sites and probably form a monolayer. The parameters deduced from the Langmuir and Freundlich lines are shown in Table 6.

4.3. Effect of Hydrogen Potential $(p H)$. To evaluate the influence of the $\mathrm{pH}$ treatment on the adsorption of phenol by our adsorbent, we carried out adsorption tests according to the following operating conditions (Table 7).

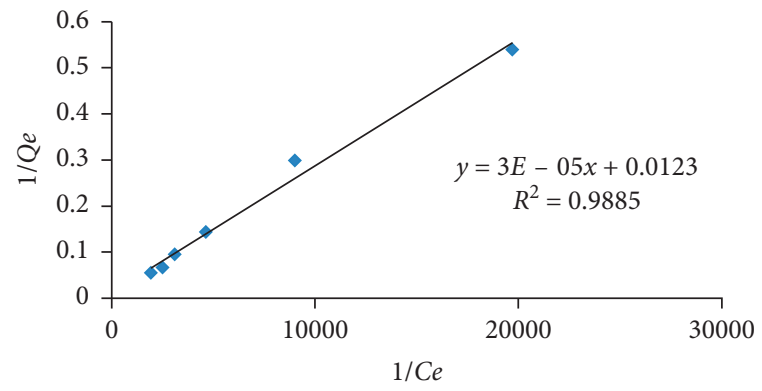

FIgURE 11: Adsorption isotherm of phenol on Sale clay, Langmuir model.

The $\mathrm{pH}$ is adjusted successively to $3.35,6.17,8.59$, and 12.51 and is kept constant during one hour of stirring, using $\mathrm{NaOH}(0.1 \mathrm{~N})$ and $\mathrm{HCl}(0.1 \mathrm{~N})$ solutions. The results (Figure 13) show the influence of $\mathrm{pH}$ on the adsorption of phenol 


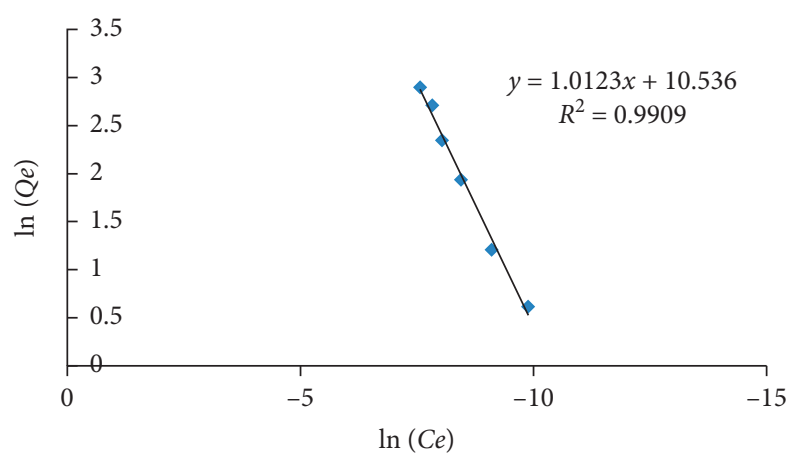

Figure 12: Adsorption isotherm of phenol on Sale clay, Freundlich model.

TAвle 6: Parameters deduced from the Langmuir and Freundlich lines.

\begin{tabular}{lcccr}
\hline & Langmuir model & \multicolumn{3}{c}{ Freundlich model } \\
$Q_{e}\left(\mathrm{mg} \mathrm{g}^{-1)}\right.$ & $K_{L}\left(\mathrm{~L} \cdot \mathrm{mg}^{-1}\right)$ & $R^{2}$ & $K_{F}\left({\left.\mathrm{mg} \cdot \mathrm{g}^{-1}\right)}^{2}\right.$ & $1 / n$ \\
\hline 83.33 & 1.2 & 0.99 & 37.42 & 1.012 \\
\hline
\end{tabular}

TABLE 7: Operating conditions of the tests studying the effect of the $\mathrm{pH}$.

\begin{tabular}{lcc}
\hline Concentration $\left(\mathrm{mg} \cdot \mathrm{L}^{-1}\right)$ & Mass of adsorbent used $\left(\mathrm{g} \cdot \mathrm{L}^{-1}\right)$ & Stirring time $(\mathrm{min})$ \\
\hline $10^{-3} \mathrm{~mol} \cdot \mathrm{L}^{-1}$ & 2.5 & 60 \\
\hline
\end{tabular}

on the adsorbent, and we can see that the best retention yield is obtained in the acidic medium, removing the phenol with a yield of $50 \%$ for a mass concentration equal to $0.9 \mathrm{~g} / \mathrm{L}$.

The removal of phenol was maximum and unperturbed when the initial $\mathrm{pH}$ of the phenol solution was between 3 and 8; a similar ability of $\mathrm{pH}$ effect was observed for the adsorption of phenol on activated carbon prepared from biomass material [4], as well as a similar trend for the adsorption of phenol red from aqueous solution on modified bentonite with maximum uptake at $\mathrm{pH} 3.0$ and a remarkable decrease upon increasing the $\mathrm{pH}$ from 3.0 to 9.0 [24].

Phenol behaves as an anion at high $\mathrm{pH}$ values [28], which produces at high $\mathrm{pH}$ a competition between $\mathrm{OH}$ ions and phenol molecules on the sorption sites resulting in a weak adsorption due to repulsion. However, at acidic $\mathrm{pH}$, a cooperative retention of phenol occurs. First, with the protonation of the $-\mathrm{OH}$ function which gives rise to nucleophilic sites on the function, these nucleophilic sites will be more attracted by the negative surface of the clay. Second, the presence of a very acidic proton favors the hydrogen bonds.

4.3.1. Thermodynamic Study of Adsorption. In the course of adsorption, the surface energy of the adsorbent can be increased or decreased, and the standard enthalpy $\left(\Delta H^{\circ}\right)$, standard entropy $\left(\Delta S^{\circ}\right)$, and standard free energy are the parameters that can describe the thermodynamics of adsorption to calculate the values of $\Delta H^{\circ}$ and $\Delta S^{\circ}$ using the following equation [31]:

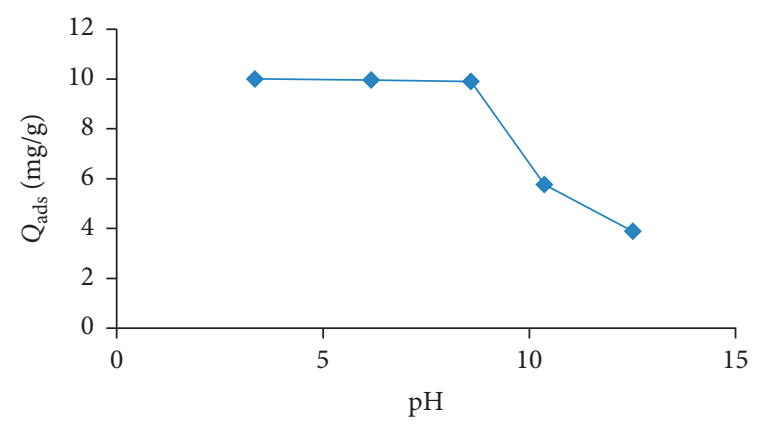

FIGURE 13: Effect of $\mathrm{pH}$ treatment on the adsorption of phenol on Sale clay.

$$
\operatorname{Ln} K_{d}=\frac{\Delta S^{\circ}}{R}-\frac{\Delta H^{\circ}}{R T}
$$

where $R$ denotes perfect gas constant $\left(R=8.314 \mathrm{~J} \cdot \mathrm{mol}^{-1} \cdot \mathrm{K}^{-1}\right)$; $T$ denotes absolute temperature of solution $(\mathrm{K}) ; K_{d}$ denotes distribution coefficient equal to $Q_{e} / C_{e}$. Equation (4) is used to calculate the values of $\Delta G^{\circ}[27,29]$ :

$$
\Delta G^{\circ}=-R \cdot T \cdot \operatorname{Ln} K_{d}
$$

The graphical presentation of the van't Hoff equation for the adsorption of phenol on our adsorbent is displayed in Figure 14.

According to Table 8 , the positive value of $\Delta S$ resulting from the adsorption of phenol corresponds to an increase in the degree of freedom in the system and indicates an affinity 


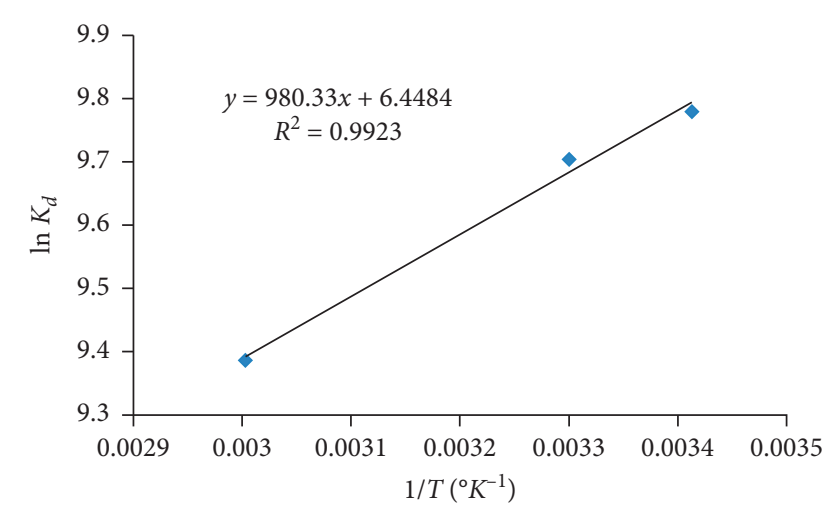

Figure 14: Van't Hoff curve for the adsorption of phenol on Sale clay.

TABLE 8: Thermodynamic parameters of phenol adsorption.

\begin{tabular}{lcrcc}
\hline$\Delta H^{\circ}\left(\mathrm{J} \cdot \mathrm{mol}^{-1}\right)$ & $\Delta S^{\circ}\left(\mathrm{J} \cdot \mathrm{mol}^{-1}\right)$ & \multicolumn{3}{c}{$\Delta G^{\circ}\left(\mathrm{J} \cdot \mathrm{mol}^{-1}\right)$} \\
& & $20^{\circ} \mathrm{C}$ & $30^{\circ} \mathrm{C}$ & $60^{\circ} \mathrm{C}$ \\
\hline-8150.21 & 53.60 & -23855.01 & -24209.21 & -26998.01 \\
\hline
\end{tabular}

of the adsorbent for the adsorbate molecules [31]. The negative value of $\Delta H, 9.8 \mathrm{~kJ} / \mathrm{mol}$, indicates an exothermic adsorption process. From this table, we noted that the values of $\Delta G$ are between -23855.01 and $-26998.01 \mathrm{~kJ} / \mathrm{mol}$, indicating that the adsorption of phenol on this material is physical in nature.

\section{Conclusion}

This work aims to study the removal of phenol on a Moroccan clay support. The kinetics of adsorption of phenol on this clay show that this material adsorbs phenol rapidly in aqueous solution. The kinetics follow the pseudo-secondorder equation. The adsorption of phenol on this material is exothermic and physical in nature, and the adsorption capacity decreased slightly with increasing temperature. Study of the effect of particle size on the adsorption capacity showed that the particle size of our material has no effect on the diffusion of phenol. The Langmuir-Freundlich isotherm model describes well the adsorption equilibrium data for phenol. These isotherms also show significant adsorption capacity with percent removal exceeding $50 \%$. The parameter optimization study showed that the adsorption yield increases as the $\mathrm{pH}$ decreases. This increase is explained by the protonation of the phenol, which leads to the increase of nucleophilic sites on the aromatic ring. These sites will be more attracted by the negative surface of the clay.

\section{Data Availability}

All the basic data that support the results of this study are contained in the article.

\section{Conflicts of Interest}

The authors declare that they have no conflicts of interest.

\section{References}

[1] A. H. Norzilah, A. Fakhru'l-Razi, T. S. Y. Choong, and A. L. Chuah, "Surface modification effects on CNTs adsorption of methylene blue and phenol," Journal of Nanomaterials, vol. 2011, Article ID 495676, 18 pages, 2011.

[2] A. El Gaidoumi, A. Chaouni Benabdallah, A. Lahrichi, and A. Kherbeche, "Adsorption du phénol en milieu aqueux par une pyrophyllite marocaine brute et traitée," Journal of Materials and Environmental Science, vol. 6, no. 8, pp. 2247-2259, 2015.

[3] O. E.-A. Ahmed Adam and A. H. Al-Dujaili, "The removal of phenol and its derivatives from aqueous solutions by adsorption on petroleum asphaltene," Journal of Chemistry, vol. 2013, Article ID 694029, 8 pages, 2013.

[4] B. H. Hameed and A. A. Rahman, "Removal of phenol from aqueous solutions by adsorption onto activated carbon prepared from biomass material," Journal of Hazardous Materials, vol. 160, no. 2-3, pp. 576-581, 2008.

[5] A. Mills, M. Bingham, C. O'Rourke, and M. Bowker, "Modelled kinetics of the rate of hydrogen evolution as a function of metal catalyst loading in the photocatalysed reforming of methanol by $\mathrm{Pt}$ (or $\mathrm{Pd}$ )/ $/ \mathrm{TiO}_{2}$," Journal of Photochemistry and Photobiology A: Chemistry, vol. 373, pp. 122-130, 2019.

[6] S. Allaoui, M. Naciri Bennani, H. Ziyat, O. Qabaqous, N. Tijani, and N. Ittobane, "Kinetic study of the adsorption of polyphenols from olive mill wastewater onto natural clay: ghassoul," Journal of Chemistry, vol. 2020, Article ID 7293189 , 11 pages, 2020.

[7] T.-L. Pham and M. H. Bui, "Removal of nutrients from fertilizer plant wastewater using Scenedesmus sp.: formation of bioflocculation and enhancement of removal efficiency," Journal of Chemistry, vol. 2020, Article ID 8094272, 9 pages, 2020.

[8] D. İpekçi, N. Kabay, S. Bunani et al., "Application of heterogeneous ion exchange membranes for simultaneous separation and recovery of lithium and boron from aqueous solution with bipolar membrane electrodialysis (EDBM)," Desalination, vol. 479, p. 114313, 2020.

[9] U. Kurtan, M. Amir, A. Y1ldı, and A. Baykal, "Synthesis of magnetically recyclable $\mathrm{MnFe}_{2} \mathrm{O}_{4} @ \mathrm{SiO}_{2} @ \mathrm{Ag}$ nanocatalyst: its high catalytic performances for azo dyes and nitro compounds reduction," Applied Surface Science, vol. 376, pp. 16-25, 2016.

[10] S. Mohebali, D. Bastani, and H. Shayesteh, "Equilibrium, kinetic and thermodynamic studies of a low-cost biosorbent for the removal of Congo red dye: acid and CTAB-acid modified celery (Apium graveolens)," Journal of Molecular Structure, vol. 1176, pp. 181-193, 2019.

[11] I. Loulidi, "Adsorptive removal of chromium (VI) using walnut shell, almond shell, coconut shell and peanut shell," Research Journal of Chemistry and Environment, vol. 23, no. 12, pp. 25-32, 2019.

[12] I. Chaari, M. Feki, M. Medhioub, J. bouzid, E. Fakhfakh, and F. Jamoussi, "Adsorption of a textile dye "Indanthrene Blue RS (C.I. Vat Blue 4)" from aqueous solutions onto smectiterich clayey rock," Journal of Hazardous Materials, vol. 172, no. 2-3, pp. 1623-1628, 2009.

[13] I. Chaari, M. Medhioub, F. Jamoussi, and A. H. Hamzaoui, "Acid-treated clay materials (Southwestern Tunisia) for removing sodium leuco-vat dye: characterization, adsorption study and activation mechanism," Journal of Molecular Structure, vol. 1223, p. 128944, 2020. 
[14] S. Bentahar, A. Dbik, M. E. Khomri, N. E. Messaoudi, and A. Lacherai, "Adsorption of methylene blue, crystal violet and Congo red from binary and ternary systems with natural clay: kinetic, isotherm, and thermodynamic," Journal of Environmental Chemical Engineering, vol. 5, no. 6, pp. 5921-5932, 2017.

[15] O. Sakin Omer, M. A. Hussein, B. H. M. Hussein, and A. Mgaidi, "Adsorption thermodynamics of cationic dyes (methylene blue and crystal violet) to a natural clay mineral from aqueous solution between 293.15 and $323.15 \mathrm{k}$," Arabian Journal of Chemistry, vol. 11, no. 5, pp. 615-623, 2018.

[16] E. Khosla, "Natural clay-an adsorbent for basic dye," Journal of Chemistry and Applied Biochemistry, vol. 2, no. 2, pp. 1-5, 2016.

[17] J. Kyzioł-Komosińska, C. Rosik-Dulewska, M. Pajak, I. Krzyewska, and A. Dzieniszewska, "Adsorption of anionic dyes onto natural, thermally and chemically modified smectite clays," Polish Journal of Chemical Technology, vol. 16, no. 4, pp. 33-40, 2014.

[18] L. Bouna, A. A. El Fakir, A. Benlhachemi, K. Draoui, S. Villain, and F. Guinneton, "Physico-chemical characterization of clays from Assa-Zag for valorization in cationic dye methylene blue adsorption," Materials Today: Proceedings, vol. 22, no. 3, pp. 22-27, 2020.

[19] K. Elass, A. Laachach, A. Alaoui, and M. Azzi, "Removal of methyl violet from aqueous solution using a stevensite-rich clay from Morocco," Applied Clay Science, vol. 54, no. 1, pp. 90-96, 2011.

[20] M. Ajbary, A. Santos, V. Morales-Flórez, and L. Esquivias, "Removal of basic yellow cationic dye by an aqueous dispersion of Moroccan stevensite," Applied Clay Science, vol. 80-81, pp. 46-51, 2013.

[21] C. Zhu, Q. Wang, X. Huang, J. Yun, Q. Hu, and G. Yang, "Adsorption of amino acids at clay surfaces and implication for biochemical reactions: role and impact of surface charges," Colloids and Surfaces B: Biointerfaces, vol. 183, p. 110458, 2019.

[22] A. M. Ahmat, T. Thiebault, and R. Guégan, "Phenolic acids interactions with clay minerals: a spotlight on the adsorption mechanisms of Gallic Acid onto montmorillonite," Applied Clay Science, vol. 180, p. 105188, 2019.

[23] M. Atrous, L. Sellaoui, M. Bouzid et al., "Adsorption of dyes acid red 1 and acid green 25 on grafted clay: modeling and statistical physics interpretation," Journal of Molecular Liquids, vol. 294, p. 111610, 2019.

[24] N. L. My Linh, T. Duong, H. Van Duc et al., "Phenol red adsorption from aqueous solution on the modified bentonite," Journal of Chemistry, vol. 2020, Article ID 1504805, 14 pages, 2020.

[25] Z. M. Yusoff, B. T. Ngwenya, and I. Parsons, "Mobility and fractionation of REEs during deep weathering of geochemically contrasting granites in a tropical setting, Malaysia," Chemical Geology, vol. 349-350, pp. 71-86, 2013.

[26] M. Yang, X. Liang, L. Ma, J. Huang, H. He, and J. Zhu, "Adsorption of REEs on kaolinite and halloysite: a link to the REE distribution on clays in the weathering crust of granite," Chemical Geology, vol. 525, pp. 210-217, 2019.

[27] I. Loulidi, F. Boukhlifi, M. Ouchabi et al., "Adsorption of crystal violet onto an agricultural waste residue: kinetics, isotherm, thermodynamics, and mechanism of adsorption," The Scientific World Journal, vol. 2020, Article ID 5873521, 9 pages, 2020.

[28] M. Moyo, M. Eusebia, C. Fidelis, and C. N. Benias, "Removal of phenol from aqueous solution by adsorption on yeast, Saccharomyces cerevisiae," IJRRAS, vol. 11, pp. 486-494, 2012.
[29] I. Loulidi, F. Boukhlifi, M. Jabri et al., "Kinetic, isotherm and mechanism investigations of the removal of basic violet 3 from water by raw spent coffee grounds," Physical Chemistry Research, vol. 8, no. 3, pp. 569-584, 2020.

[30] M. Pashai Gatabi, H. Milani Moghaddam, and M. Ghorbani, "Point of zero charge of maghemite decorated multiwalled carbon nanotubes fabricated by chemical precipitation method," Journal of Molecular Liquids, vol. 216, pp. 117-125, 2016.

[31] F. Boukhlifi and A. Bencheikh, "Characterization of natural biosorbents used for the depollution of waste water," Annales de Chimie Science des Matériaux, vol. 25, no. 2, pp. 153-160, 2000 . 